\title{
Persistent violent offending: what do we know?
}

\author{
SHEILAGH HODGINS
}

\begin{abstract}
Summary A great deal is known about men who display a stable pattern of antisocial behaviour since childhood. However, more research is needed to identify subtypes within this population so as to further understanding of the causal processes that initiate and maintain violent behaviours and to identify interventions that specifically target the deficits presented by each subtype. Evidencebased practice means not only using treatments proven to be effective but also basing conceptualisations of disorders on scientific evidence.
\end{abstract}

\section{Declaration of interest None.}

We know that many more men than women become persistent violent offenders and that a very small group, less than $5 \%$ of the male population, commit between $50 \%$ and $70 \%$ of all the violent crimes (Moffitt, 1993; Hodgins, 1994). These men fulfil criteria for diagnoses of conduct disorder before 10 years of age, antisocial personality disorder and psychopathy (according to the Psychopathy ChecklistRevised (PCL-R); Hare, 1991) in adulthood, and have been labelled as life course persistent offenders. This population, however, is heterogeneous. Identifying the distinct subgroups is essential to unravel the complex and dynamic interactions of biological, psychological and social factors that initiate and maintain the violent behaviour over the life span and to establish interventions that address the specific deficits characterising each subgroup.

\section{SUBGROUPS OF PERSISTENT VIOLENT OFFENDERS}

Within the population of persistent violent offenders with a stable pattern of antisocial behaviour since childhood, evidence suggests that there are at least three subgroups with distinct aetiologies and response to treatments. This population first divides in half based on the presence or absence of comorbid anxiety disorders (Sareen et al, 2004). This evidence from adults is consistent with developmental studies of young children showing that among those with early-onset conduct problems, one subgroup displays high levels of internalising problems and another does not (Gilliom $\&$ Shaw, 2004). The non-anxious half of this population contains a subgroup who present the syndrome of psychopathy as diagnosed by the PCL-R, which requires full-blown expression of the traits of arrogant and deceitful interpersonal behaviour and deficient affective experience (Cooke $\&$ Michie, 2001) and a much larger group who do not meet the diagnostic cut-off for psychopathy, but who obtain higher scores on the traits than men in the general population. By contrast, the highly anxious males with antisocial personality disorder or conduct disorder present a distinctively different set of traits.

During the past 25 years, evidence has accumulated that men within this population with psychopathy diagnosed according to PCL-R differ markedly from the others. They commit more violent offences, engage in both instrumental and reactive aggression and more quickly reoffend when released. They display a profound emotional dysfunction characterised by impaired recognition of fear and sadness in faces and voices, low levels of stress reactivity indexed by heart rate, skin conductance and cortisol, and a cognitive style dominated by reward and a failure to recognise punishment. Performance on IQ and standard neuropsychological tests is within normal limits (Patrick, 2006).

Among children with early-onset conduct disorder, there is a subgroup with stable, callous-unemotional traits that are thought to represent the antecedents of the psychopathic traits. There are as yet no studies that have followed such children into adulthood, but the available evidence suggests that boys who present both conduct disorder and callous-unemotional traits share many features with adult psychopathy. Compared with boys with conduct disorder alone, boys with both conduct disorder and such traits present more severe conduct problems, more aggressive behaviour and violent crimes at an earlier age. They demonstrate a preference for risky behaviours that are novel and exciting to them, less reactivity to threatening and emotionally distressing stimuli and a muted cortisol stress response. They show less ability to recognise sadness in faces and vocalisations and are more impaired on tests of moral reasoning and empathy. In addition, these boys have difficulty changing behaviours that are initially rewarded and subsequently punished and emphasise the positive consequences of aggressive behaviour but fail to appreciate the negative consequences. Not surprisingly given these characteristics, the boys with both conduct disorder and callous-unemotional traits are less responsive to parenting practices and most particularly to punishment. In addition to the emotional deficits, children with callous-unemotional traits also display cognitive abnormalities similar to those observed among adult men with psychopathy, and have higher IQ scores than other boys with conduct disorder (Blair, 2003; Frick \& Marsee, 2006).

Boys with conduct problems who do not present callous-unemotional traits display aggressive behaviour that is emotionally charged in response to provocations that may be real or result from their tendency to perceive hostility in others, even in neutral faces (Dadds et al, 2006). These children report emotional distress, are more reactive to distress and especially to negative emotional stimuli. They are, however, responsive to good parenting practices and benefit when their parents complete parent training programmes (Hawes \& Dadds, 2005). These boys present high levels of impulsivity, a tendency towards anger and like children with anxiety disorders have lower than average verbal abilities (Frick \& Marsee, 2006).

The place of attention-deficit hyperactivity disorder (ADHD) in persistent violent offending and in the characterisation of the proposed subgroups remains unclear (Waschbusch, 2002). This is often comorbid with conduct disorder and the combination 
is predictive of criminality in adulthood. Among boys with conduct disorder and ADHD, it is callous-unemotional traits and not ADHD symptoms that are associated with aggression and delinquency. Further, boys with such traits without ADHD have been shown to have the highest rates of aggressive behaviour and delinquency (Frick \& Marsee, 2006). Recent evidence demonstrates that both the genotype and the phenotype of ADHD are heterogeneous, and that IQ mediates, at least in part, psychosocial functioning, including violent offending, in adulthood (Mill et al, 2006). Boys with conduct disorder and ADHD obtain lower IQ scores and are more impulsive than boys with only conduct disorder. Inattention precedes the onset of conduct disorder, allowing for the possibility that early intervention could interrupt the development of conduct disorder (Simonoff, 2000; Waschbusch, 2002).

Available evidence suggests that the aetiology in the three subgroups of males with early-onset stable antisocial behaviour differs. A meta-analysis of twin and family studies reported a modest genetic contribution ( 0.41 heritability) to the development of early-onset and stable antisocial behaviour, including substance misuse (Rhee $\&$ Waldman, 2002), but depending on the definition of the phenotype other studies report much higher heritability coefficients (Young et al, 2000). Recent evidence suggests that callous-unemotional traits are also heritable. For example, a recent study of young twins in the UK has shown that the combination of conduct problems and callous-unemotional traits is much more heritable (heritability coefficient 0.81 ) than conduct problems alone (heritability coefficient 0.30) (Viding et al, 2005). This is consistent with studies of older participants showing high heritability for psychopathic traits (Blonigen et al, 2003; Taylor et al, 2003; Larsson et al, 2006). These results indicate that from conception onwards individuals who display early-onset stable antisocial behaviour differ from the rest of the population and that the subgroup who will develop callous-unemotional traits differ from the others. Genes modify the individual's interaction with their environment, hence each of the subtypes would be reacting to and selecting environments differently from conception onwards. Interestingly, this would mean that the subgroups would react differently during the prenatal period when individual thresholds for stress reactivity of the hypothalamic-pituitary-adrenal axis are set (Susman, 2006). This could be one of the reasons why one sub-group displays high anxiety levels and another presents abnormally low levels.

As is hypothesised for other complex disorders, each of the genes involved in antisocial and aggressive behaviour may in teract with a specific environmental factor to determine outcome. For example, a functional polymorphism in the promoter of the monoamine oxidase A gene had previously been associated with persistent aggressive behaviour in animals and in one human pedigree. In a birth cohort, neither the low nor high activity allele was associated with violent behaviour in adulthood. The males in the cohort who carried the low activity allele and who experienced physical abuse during childhood were three times more likely than the men with the same allele who had not experienced abuse to present conduct disorder and ten times more likely to commit violent criminal offences. Physical abuse in the absence of the gene did not increase the risk of conduct disorder or violent crime (Caspi et al, 2002). Two studies have replicated this finding in White males (Foley et al, 2004; Widom \& Brzustowicz, 2006). Thus, individuals who differed in genetic profile reacted differently to their environments, and even to a severe event such as physical abuse.

\section{IMPLICATIONS OF THE FAILURE TO IDENTIFY SUBTYPES}

The failure to distinguish subtypes within the population of males who show an early-onset and stable pattern of antisocial and aggressive behaviour blocks progress in research aimed at furthering understanding of persistently violent offenders and in efforts to identify effective treatments. Consider for example, studies using singlephoton emission computed tomography (SPECT), magnetic resonance imaging (MRI), and functional MRI to investigate brain structure and functioning. These studies have focused largely on men who met criteria for psychopathy. Participants have been characterised using different cut-off scores and different scales, and little attention has been paid to the composition of the comparison group. Results have been inconsistent and difficult to interpret. One reason might be that the comparison group included offenders with and without anxiety disorders. A recent fMRI study comparing boys with and without conduct disorder illustrates the problem. Contrary to the hypothesis, no differences in activity in the amygdala were observed when viewing negative pictures. This absence of a difference, however, was due to high anxiety scores among some of the boys with conduct disorder. Post hoc analyses showed that anxiety scores, as would be expected, were related to amygdala activation and aggressive behaviour scores were related to amygdala inactivity (Sterzer et al, 2005). These results clearly suggest that a more accurate description of the subtypes is needed to unravel the aetiology of early-onset stable antisocial behaviour.

The failure to characterise subtypes within this population may also lead to difficulty in interpreting the evaluations of treatment programmes. It has been known for a number of years that parent training programmes reduce conduct problems among young children (Farmer et al, 2002). A recent study showed that children with conduct disorder but without callousunemotional traits benefited most, whereas those with such traits only learned when reward was used. Time-out, although an effective intervention for the children without callous-unemotional traits, failed to reduce inappropriate behaviours displayed by the children with such traits (Dadds et al, 2005). Insensitivity to punishment is a key feature of psychopathy and of children with conduct disorder and callous-unemotional traits, but not of the other subgroups (Dadds \& Salmon, 2003). Taking account of the presence or absence of such characteristics when developing treatment programmes will increase their specificity and thereby effectiveness.

Although several offender rehabilitation programmes have been shown to be as effective as most accepted medical treatments, there is little evidence about the characteristics of offenders who benefit and those that do not (Welsh et al, 2002). Richer and more complete characterisations of the subtypes of persistent violent offenders would lead to the development of treatments that directly target deficits. For example, one of the characteristics of boys with conduct disorder and callousunemotional traits and offenders with psychopathy is their altered perception of reward and punishment. Both in neuropsychological tests and in real-life situations, they focus on rewards and ignore punishments. Consequently, they persistently miss 
the signal - the punishment - that a behaviour is inappropriate. As children, this may be one of the key mechanisms that promotes their antisocial behaviour and that limits their access to the usual socialising experiences such as sports and other community activities, and eventually even to school. The problem persists into adulthood and is present, for example, later in life when they are incarcerated and enrolled in an offender rehabilitation programme. Many of these programmes include a module designed to develop problem-solving skills. Problem-solving is divided into four steps. Step one involves identifying the problem, step two generating as many responses as possible, step three assessing the likely positive and negative consequences of each possible response, and the final step selecting the best response. At step three, men with psychopathy and boys with conduct disorder and callousunemotional traits would focus on rewards and be less able than others to identify possible negative outcomes. To help them learn to solve problems would first require teaching them to identify negative outcomes. For the adults, this may be particularly difficult as they have had so many years without this skill.

\section{REFERENCES}

Blair, R. J. R. (2003) Neurobiological basis of psychopathy. British Journal of Psychiatry, 182, 5-7.

Blonigen, D. M., Carlson, S. R., Krueger, R. F., et al (2003) A twin study of self-reported psychopathic personality traits. Personality and Individual Differences, 35, 179-197.

Caspi, A., McClay, J., Moffitt, T., et al (2002) Role of genotype in the cycle of violence in maltreated children. Science, 297, 851-854.

Cooke, D. J. \& Michie, C. (200I) Refining the construct of psychopathy: towards a hierarchical model. Psychological Assessment, 13, 17|-188.

Dadds, M. R. \& Salmon, K. (2003) Punishment insensitivity and parenting: temperament and leaning as interacting risks for antisocial behaviour. Clinical Child and Family Psychology Review, 6, 69-86.

SHEILAGH HODGINS, PhD, Department of Forensic Mental Health Science, Institute of Psychiatry, King's College London SE5 8AF, UK. Email: s.hodgins@iop.kcl.ac.uk

Dadds, M. R., Fraser, J., Frost, A., et al (2005)

Disentangling the underlying dimensions of psychopathy and conduct problems in childhood: a community study. Journal of Consulting and Clinical Psychology, 73, 400-410.

Dadds, M. R., Perry, Y., Hawes, D. J., et al (2006) Attention to the eyes reverses fear-recognition deficits in child psychopathy. British Journal of Psychiatry, $\mathbf{1 8 9}$ 280-28I.

Farmer, E. M. Z., Compton, S. N., Burns, B. J., et al (2002) Review of the evidence base for treatment of childhood psychopathology: externalizing disorders. Journal of Consulting and Clinical Psychology, 70, 12671302.

Foley, D. E., Eaves, L. J., Wormley, B., et al, (2004) Childhood adversity, monoamineoxidase A genotype, and risk for conduct disorder. Archives of General Psychiatry, 6I, 738-744.

Frick, P. J. \& Marsee, M. A. (2006) Psychopathy and developmental pathways to antisocial behavior in youth In Handbook of Psychopathy (ed. C. J. Patrick), pp. 353374. Guilford Press.

Gilliom, M. \& Shaw, D. S. (2004) Codevelopment of externalizing and internalizing problems in early childhood. Development and Psychopathology, 16 313-333.

Hare, R. D. (1991) The Hare Psychopathy ChecklistRevised. Multi-Health Systems.

Hawes, D. J. \& Dadds, M. R. (2005) The treatment of conduct problems in children with callous/unemotional traits. Journal of Consulting and Clinical Psychology, 73. 737-741.

Hodgins, S. (1994) Status at age 30 of children with conduct problems. Studies of Crime and Crime Prevention, 3, $41-62$.

\section{Larsson, H., Andershed, H. \& Lichtenstein, P.} (2006) A genetic factor explains most of the variation in psychopathic personality. Journal of Abnormal Psychology II5, 22I-230.

Mill, J., Caspi, A., Williams, B.W., et al (2006) Prediction of heterogeneity in intelligence and adult prognosis by genetic polymorphisms in the dopamine system among children with attention-deficit/ hyperactivity disorder. Archives of General Psychiatry, 63 462-469.

Moffitt, T. E. (1993) Adolescence-limited and lifecourse-persistent antisocial behaviour: a developmental taxonomy. Psychological Bulletin, 100, 674-701.

Patrick C. J. (2006) Back to the future: Cleckley as a guide to the next generation of psychopathy research. In
Handbook of Psychopathy (ed. C. J. Patrick), pp. 605-617. Guilford.

Rhee, S. H. \& Waldman, I. D. (2002) Genetic and environmental influences on antisocial behaviour: a meta-analysis of twin and adoption studies. Psychological Bulletin, 128, 490-529.

Sareen, J., Stein, M. B., Cox, B. J., et al (2004) Understanding comorbidity of anxiety disorders with antisocial behaviour. Journal of Nervous and Mental Disease, 192, 178-186.

Simonoff, E. (2000) Extracting meaning from comorbidity: Genetic analyses that make sense. Journal of Child Psychology and Psychiatry, 4I, 667-674.

Sterzer, P., Stadler, C., Krebs, A., et al (2005) Abnormal neural responses to emotional visual stimuli in adolescents with conduct disorder. Biological Psychiatry, 57, 7-15.

Susman, E. (2006) Psychobiology of persistent antisocial behavior: stress, early vulnerabilities and the attenuation hypothesis. Neuroscience and Biobehavioral Reviews, 30, 376-389.

Taylor, J., Loney, B. R., Bobadilla, L., et al (2003) Genetic and environmental influences on psychopathy trait dimensions in a community sample of male twins. Journal of Abnormal Child Psychology, 3I, 633-645.

Viding, E., Blair, R. J. R., Moffitt, T. E., et al (2005) Evidence for substantial genetic risk for psychopathy in 7 year olds. Journal of Child Psychology and Psychiatry, 46 592-597.

Waschbusch, D. A. (2002) A meta-analytic examination of comorbid hyperactive-impulsiveattention problems and conduct problems. Psychological Bulletin, 128, 118-150.

Welsh, B. C., Farrington, D. P., Sherman, L., et a (2002) What do we know about crime prevention. International Annals of Criminology, 40, II-3I.

Widom, C. S. \& Brzustowicz, L. M. (2006) MAOA and the 'cycle of violence': childhood abuse and neglect, MAOA genotype, and risk for violent and antisocial behaviour. Biological Psychiatry, 60, 684-689.

Wong, S. (2000) Psychotic offenders. In Violence, Crime and Mentally Disordered Offenders: Concepts and Methods for Effective Treatment and Prevention (eds S. Hodgins \& R. Müller-Isberner), pp. 87-II2. John Wiley.

Young, S. E., Stalling, M. C., Corley, R. P., et al (2000) Genetic and environmental influences on behavioural disinhibition. American Journal of Medical Genetics (Neuropsychiatric Genetics), 96, 684-695. 